\title{
Risk of spontaneous preterm birth in relation to maternal experience of serious life events during pregnancy
}

This article was published in the following Dove Press journal:

International Journal of Women's Health

24 February 2014

Number of times this article has been viewed

\author{
Yasmin V Barrios' \\ Sixto E Sanchez ${ }^{2,3}$ \\ Chunfang Qiu ${ }^{4}$ \\ Bizu Gelaye' \\ Michelle A Williams' \\ 'Department of Epidemiology, \\ Harvard School of Public Health, \\ Boston, MA, USA; ${ }^{2}$ Department of \\ Obstetrics and Gynecology, Hospital \\ Dos de Mayo, ${ }^{3}$ Universidad Nacional \\ Mayor de San Marco, Lima, Peru, \\ ${ }^{4}$ Center for Perinatal Studies, Swedish \\ Medical Center, Seattle, WA, USA
}

Background: The purpose of this study was to examine the risk of preterm birth (PTB) in relation to serious life events experienced during pregnancy in Peruvian women.

Methods: This case-control study included 479 PTB cases and 480 term controls. In-person interviews asked information regarding sociodemographics, medical and reproductive histories, and serious life events experienced during pregnancy. Multivariate logistic regression procedures were used to estimate adjusted odds ratios (ORs) and 95\% confidence intervals (CIs).

Results: Compared with women who did not experience a serious life event during pregnancy, those who experienced the following life events had a more than two-fold increased odds of PTB: death of first-degree relative (adjusted OR 2.10; 95\% CI 1.38-3.20), divorce or separation (adjusted OR 2.09; 95\% CI 1.10-4.00), financial troubles (adjusted OR 2.70; 95\% CI 1.85-3.94), or serious fight with partner (adjusted OR 2.40; 95\% CI 1.78-3.17). Women who experienced any serious life events during pregnancy had higher odds (adjusted OR 2.29; 95\% CI 1.65-3.18) of suffering spontaneous preterm labor and preterm premature rupture of membranes (adjusted OR 2.19; 95\% CI 1.56-3.08), compared with women who did not experience any such events. Associations of similar directions and extent were observed for severity of PTB (ie, very, moderate, or late PTB). The magnitude of the associations increased as increased frequency of serious life events $\left(P_{\text {trend }}<0.001\right)$.

Conclusion: Experiencing serious life events during pregnancy was associated with increased odds of PTB among Peruvian women. Interventions aimed at assisting women experiencing serious life events may reduce the risk of PTB. Future studies should include objective measures of stress and stress response to understand better the biological underpinnings of these associations.

Keywords: preterm birth, serious life events, Peru

\section{Introduction}

Preterm birth (PTB), defined as delivery before completing 37 weeks' gestation, is a growing global public health problem. ${ }^{1}$ PTB is the leading cause of mortality in children under 5 years of age, ${ }^{1}$ and is a direct cause of at least $27 \%$ of all neonatal deaths. $^{2}$ Of the live births reported in 2010 worldwide, $11.1 \%$, or 14.9 million, were estimated to be PTBs. In Latin America, the estimates indicate that, of the total 10.2 million live births, $8.4 \%$ were preterm. ${ }^{3}$

While the etiologies of PTB are not yet fully understood, a number of risk factors have been identified. The commonly recognized pathways leading to PTB include infection, inflammation, placental abruption, and maternal/fetal hypothalamic-pituitary-adrenal axis activation due to acute or chronic exposure
Correspondence: Yasmin V Barrios Department of Epidemiology, Harvard School of Public Health, 677 Huntington Ave, Kresge 502A, Boston, MA 02115, USA

$\mathrm{Tel}+\mathrm{I} 617432$ II 08

Fax +I 6175667805

Email ybarrios@hsph.harvard.edu 
to psychological stressors. ${ }^{4}$ Maternal psychological stress (hereafter referred to as stress), in the form of acute, chronic, pregnancy-related, or other life event-related stressors, is emerging as an important modifiable social determinant of PTB. Investigators have discussed several mechanistically relevant theses concerning the role of stress as a determinant of PTB. For example, stress is known to upset the balance between neuroendocrine and immunological pathways, that may set into motion the events leading to spontaneous preterm labor ${ }^{5,6}$ and preterm premature rupture of membranes. Antepartum stress has also been linked to behaviors including substance abuse, ${ }^{7}$ mood and anxiety disorders, ${ }^{8}$ and underutilization of prenatal care, ${ }^{9}$ and these factors have been associated with PTB.

Research regarding the association between stress and PTB has yielded conflicting results, primarily attributed to varying measures of stress, study design, and underlying risk differences across populations studied and differences in timing and types of stressors. One study evaluating PTB risk in three different ethnic groups living in the US found that stress experienced during pregnancy was the one consistently identified risk factor for all three groups. ${ }^{10}$ Investigators have studied specific types of events, such as experiencing a death, illness, or natural disaster, and found associations with risk of PTB. ${ }^{11,12}$ A Danish study of life events, including physical illness or death of family or children, abuse, problems with partner, problems with the law, and financial stressors, found that it was the woman's overall assessment of stress caused by those life events that was associated with PTB and not the occurrence of specific events. ${ }^{13}$ Studies in Europe and South America have shown that the significance and strength of associations of stressful events with PTB varied based on the timing of exposure. ${ }^{11-14}$ Some investigators have found that pregnancy-related stress was a better predictor of PTB than general stress, ${ }^{15}$ while another study that compiled a stress score based on life events and a general health questionnaire found no association, but suggested that evaluating specific types of life events could be important. ${ }^{16}$ An accumulating body of evidence has shown that the prevalence of PTB is increasing globally, and this prevalence is expected to increase primarily in low and middle income countries, such as Peru. ${ }^{17}$ Given the growing problem of PTB, it is important to explore how maternal stress, which can be defined using numerous measures, such as serious life events, chronic stress, anxiety, depression, or perceived stress, ${ }^{2}$ contributes to the problem. This is of vital importance, especially since women living in poverty may be more prone to experiencing these events at a higher frequency and intensity, and they may also suffer higher rates of poor birth outcomes, such as low birth weight and short gestational age. ${ }^{18}$

To the best of our knowledge, no published work has evaluated the risk of PTB in relation to serious life events among low income Peruvian women. A recent study of pregnancy outcomes in Peru found that PTB occurred in 12.2\% of women, ${ }^{19}$ reflecting the serious need to investigate PTB further. We hypothesized that serious life events experienced during pregnancy are associated with an increased PTB risk among low income women in Lima, Peru.

\section{Materials and methods Study population and case selection}

Detailed methods have been described previously. ${ }^{17}$ This casecontrol study was conducted among women who delivered live births from January 2009 through July 2010 at the Hospital Nacional Dos de Mayo, the Instituto Nacional Materno Perinatal de Lima, and the Hospital Edgardo Rebagliati Martins in Lima, Peru. The study procedures and protocol were approved by the ethical review boards of the participating institutions. Women with singleton pregnancies without any gross malformations who spontaneously delivered before completing 37 weeks of gestation were defined as cases. Women from the same hospital, delivering immediately after a case patient and who delivered a singleton infant at term $(\geq 37$ weeks of gestation) were defined as controls. There was no difference in sociodemographic and lifestyle characteristics between the groups of women with prior PTB, a risk factor for consequent PTB. Spontaneous PTB cases at participating hospitals were identified by monitoring all deliveries at postpartum wards on a daily basis. ${ }^{17} \mathrm{~A}$ total of 515 eligible cases were identified and approached. Of those, a total of 479 (93\%) eligible cases agreed to participate in the study. A total of 546 eligible controls were identified and approached, and of those, 480 (88\%) agreed to participate. Written informed consent was sought and obtained prior to participation in the study.

\section{Data collection and variable definition}

Those who provided informed consent were asked to participate in a 45-minute in-person interview using a Spanish-language structured questionnaire. The questionnaire, administered by experienced and trained research personnel, collected data about maternal sociodemographic, behavioral, reproductive, and medical histories. Trained obstetricians (research fellows) reviewed labor and delivery medical records as well as prenatal medical records using a standardized abstraction form to collect information about medical and reproductive histories, blood pressure values, 
any pregnancy complications experienced by the participant, and the condition of the newborn after delivery. ${ }^{17,20}$

We defined PTB in accordance with the guidelines set by the American College of Obstetricians and Gynecologists. ${ }^{21}$ The date of the last menstrual period was used to define gestational age and confirmed by an ultrasound examination before 20 weeks of gestation. PTB cases were categorized based on the three pathophysiological groups previously described, ie, spontaneous preterm labor and birth and preterm premature rupture of membranes. ${ }^{22}$ Spontaneous preterm labor and delivery cases included women whose medical records reported that a physician diagnosed spontaneous labor onset (with intact fetal membranes) and delivery occurred prior to completing 37 weeks' gestation. Preterm premature rupture of membranes cases included women whose medical records reported that a physician diagnosed rupture of fetal membranes (prior to onset of labor) and delivery before completing 37 weeks of gestation. When medical intervention was identified as the reason for the woman delivering prior to 37 completed weeks of gestation, she was not eligible for this study. ${ }^{23}$ Preterm birth cases were also further categorized based on gestational age at delivery (ie, very PTB, defined as those who delivered prior to completing $<32$ weeks' gestation; moderate PTB, defined as delivering between 32 and 34 weeks' gestation; and late PTB, defined as delivering between 34 and 36 weeks' gestation).

Information gathered from the interview included age, marital and employment status during pregnancy, medical history, and substance (alcohol and cigarette) consumption during pregnancy. Exposure to serious life events during pregnancy was determined by a previously used standard list of life events. The women responded to the questions: "Over the past 6-9 months (during the pregnancy), did any of the following life events occur?" The list of events included: death of a first-degree relative or significant other; divorce or separation from your partner; fired or forced to change jobs; financial trouble or bankruptcy; a serious fight or argument with husband or boyfriend; and attendance at the wedding of a close friend or relative. Response options for each event were: no; once; twice; three or more times. Women who responded "no" to any of these life events were classified as never exposed to any serious life events during their pregnancy. Other covariates considered in this analysis included maternal age, reproductive history, and medical history. Also considered were maternal prepregnancy weight, educational attainment, annual household income, occupation, cigarette smoking, and alcohol consumption during pregnancy. Maternal age at the time of interview was expressed in years. Parity was reported as the number of previous pregnancies lasting more than 22 weeks' gestation. Maternal educational attainment was based on self-reports.

\section{Statistical analysis}

Using chi-squared tests, we examined the distribution of maternal sociodemographic characteristics, and medical and reproductive histories according to preterm and term delivery status. In order to estimate the association between exposure to serious life events and the risk of PTB, we used logistic regression procedures to calculate maximum likelihood estimates of odds ratios (ORs) and 95\% confidence intervals (CIs) that were also adjusted for confounding. ${ }^{24}$ The following variables were considered as possible confounders: age, marital status, educational attainment, parity, planned pregnancy, prepregnancy weight, use of prenatal care services, employment status, smoking cigarettes, consuming alcohol, and use of illicit drugs during pregnancy. Age was entered into the regression analysis as a continuous variable. The remaining variables were analyzed as dichotomous variables. These potential confounders were tested individually in a logistic model and the unadjusted and adjusted ORs were compared. Final logistic regression models included covariates only if their inclusion changed the unadjusted ORs by at least $10 \% .{ }^{24}$ The final models were adjusted for maternal age, prepregnancy weight, pregnancy not planned, and not receiving prenatal care, ie, the variables that met the requirement for inclusion. These procedures were also used in stratified analyses to assess risk of subtypes of PTB (ie, spontaneous preterm labor and delivery, preterm premature rupture of membranes, very $\mathrm{PTB}$, moderate $\mathrm{PTB}$, and late PTB). All continuous variables are presented as the mean \pm standard deviation. All reported $P$-values are two-tailed and CIs were calculated at the $95 \%$ level. Before beginning the study, we estimated that a study sample size of 400 cases and 400 controls would be sufficient ( $>85 \%$ power) for estimating ORs of $\geq 2.0$ if the exposure frequencies were $\geq 10 \%$, and if we set significance at 0.05 . All analyses were performed using Stata version 9.0 statistical software (Statacorp, College Station, TX, USA).

\section{Results}

Sociodemographics and reproductive characteristics of PTB cases and controls are presented in Table 1. We found that cases and controls were similar with regards to a number of characteristics, ie, the mean maternal age was 28 years, approximately $40 \%$ of the women were primiparous, about $67 \%$ had a high school education or less, and $40 \%$ were employed during their pregnancy. 
Table I Sociodemographic and reproductive characteristics and infant outcomes in the study population, Lima, Peru, 2009-20I0

\begin{tabular}{|c|c|c|c|c|c|}
\hline \multirow[t]{3}{*}{ Characteristics } & \multicolumn{4}{|c|}{ Preterm birth } & \multirow[t]{3}{*}{$P$-value } \\
\hline & \multicolumn{2}{|c|}{ Controls $(n=480)$} & \multicolumn{2}{|c|}{ Cases $(n=479)$} & \\
\hline & $\mathbf{n}$ & $\%$ & $\mathbf{n}$ & $\%$ & \\
\hline Maternal age at delivery (years)* & $28.3 \pm 6.52$ & & $8.2 \pm 6.6$ & & 0.74 \\
\hline Maternal age at delivery (years) & & & & & 0.49 \\
\hline$<20$ & 42 & 8.8 & 49 & 10.2 & \\
\hline $20-29$ & 235 & 49.0 & 228 & 47.6 & \\
\hline $30-34$ & 94 & 19.6 & 107 & 22.3 & \\
\hline$\geq 35$ & 109 & 22.7 & 95 & 19.8 & \\
\hline Primiparity & 199 & 41.5 & 205 & 42.8 & 0.68 \\
\hline High school education or lower & 335 & 68.9 & 319 & 66.6 & 0.29 \\
\hline Employed during pregnancy & 195 & 40.6 & 177 & 37.0 & 0.24 \\
\hline Planned pregnancy & 209 & 43.5 & 152 & 31.7 & $<0.001$ \\
\hline No prenatal care & 19 & 4.0 & 75 & 15.7 & $<0.001$ \\
\hline No prenatal vitamins & 68 & 14.2 & 119 & 24.8 & $<0.001$ \\
\hline Any smoking during pregnancy & & & & & 0.144 \\
\hline No & 426 & 88.8 & 410 & 85.6 & \\
\hline Yes & 54 & 11.3 & 69 & 14.4 & \\
\hline Alcohol use during pregnancy & 157 & 32.7 & 150 & 31.3 & 0.64 \\
\hline Prepregnancy weight (kg) & $58.0 \pm 9.8$ & & $56.7 \pm 10.0$ & & $<0.001$ \\
\hline Infant birth weight (g) & $3392 \pm 462$ & & $1999 \pm 663$ & & 0.04 \\
\hline Low birth weight infant $(<2,500 \mathrm{~g})$ & 14 & 2.9 & 381 & 76.5 & $<0.001$ \\
\hline
\end{tabular}

Note: *Mean \pm standard deviation. "Student's t-test.

Compared with controls, cases were less likely to have planned the pregnancy, taken prenatal vitamins, and less likely to have received prenatal care.

Unadjusted and adjusted ORs of PTB according to maternal exposure to serious life events during pregnancy are summarized in Table 2. Adjustment was made for confounding by including maternal age, prepregnancy weight, unplanned pregnancy, and not receiving prenatal care in the final logistic regression model. Compared with women who did not experience any serious life events during pregnancy, the odds of PTB were increased more than two-fold for women who experienced the following events: death of a first-degree relative (adjusted OR 2.10; 95\% CI 1.38-3.20), divorce or separation (adjusted OR 2.09; 95\% CI 1.10-4.00), financial troubles (adjusted OR 2.70; 95\% CI 1.85-3.94), or a serious fight with their partner (adjusted OR 2.40; 95\% CI 1.78-3.17). As the total number of events experienced during pregnancy increased, the odds of PTB also increased ( $P$ for trend $<0.001)$. For instance, women who experienced three or more serious life events during pregnancy had a 3.62-fold (adjusted OR 3.62; 95\% CI 2.08-6.29) increased odds of delivering preterm compared with women who experienced no events during pregnancy.

The adjusted ORs of preterm subtypes, spontaneous preterm labor, and preterm premature rupture of membranes, according to maternal exposure to serious life events, are shown in Table 3. Compared with women who did not experience any serious life events during pregnancy, the odds of spontaneous preterm labor and of preterm premature rupture of membranes increased by 2.5 -fold and 2.0 -fold, respectively, for women who experienced the death of a relative or significant other, a divorce or separation, financial troubles, or a serious fight with their partner. Compared with women who did not experience any serious life events, experiencing being fired or forced to change jobs or the wedding of a close relative or friend were associated with an increased odds of spontaneous preterm labor, but the associations did not reach statistical significance. Women who experienced any serious life events had 2.29-fold higher odds (adjusted OR 2.29; 95\% CI 1.65-3.18) of experiencing spontaneous preterm labor and 2.19-fold higher odds (adjusted OR 2.19; 95\% CI 1.56-3.08) of experiencing preterm premature rupture of membranes compared with women who did not experience any such life events during pregnancy. Those who experienced two events during the study pregnancy had a 2.73-fold higher odds (adjusted OR 2.73; 95\% CI 1.76-4.26) of spontaneous preterm labor and a 2.89-fold higher odds (adjusted OR 2.89; 95\% CI 1.85-4.53) of preterm premature rupture of membranes. Women who experienced three or more events had a 4.26-fold higher odds (adjusted OR 2.26 ; 95\% CI 2.26-8.03) of spontaneous preterm labor and a 3.16-fold higher odds (adjusted OR 3.16; 95\% CI 1.63-6.14) 
Table 2 Odds ratios and $95 \%$ confidence intervals of preterm birth according to maternal exposure to serious life events during pregnancy, Lima, Peru, 2009-2010

\begin{tabular}{|c|c|c|c|c|c|c|}
\hline \multirow[t]{2}{*}{ Life events } & \multicolumn{2}{|c|}{ Controls $(n=480)$} & \multicolumn{2}{|c|}{ All PTB ( $n=479)$} & \multirow[t]{2}{*}{ Unadjusted OR (95\% CI) } & \multirow[t]{2}{*}{ Adjusted OR* $(95 \% \mathrm{Cl})$} \\
\hline & $\mathbf{n}$ & $\%$ & $\mathbf{n}$ & $\%$ & & \\
\hline \multicolumn{7}{|c|}{ Death of a first-degree relative/significant other } \\
\hline No & 440 & 91.7 & 403 & 84.1 & 1.00 (referent) & 1.00 (referent) \\
\hline Yes & 40 & 8.3 & 76 & 15.9 & $2.07(1.38-3.1 \mathrm{I})$ & $2.10(1.38-3.20)$ \\
\hline \multicolumn{7}{|c|}{ Divorce or separation } \\
\hline No & 465 & 96.9 & 446 & 93.1 & 1.00 (referent) & 1.00 (referent) \\
\hline Yes & 15 & 3.1 & 33 & 6.9 & $2.29(1.23-4.28)$ & $2.09(1.10-4.00)$ \\
\hline \multicolumn{7}{|c|}{ Fired or forced to change job } \\
\hline No & 459 & 95.6 & 458 & 95.6 & 1.00 (referent) & 1.00 (referent) \\
\hline Yes & 21 & 4.4 & 21 & 4.4 & $1.00(0.54-1.86)$ & $1.08(0.57-2.03)$ \\
\hline \multicolumn{7}{|c|}{ Financial trouble or bankruptcy } \\
\hline No & 433 & 90.2 & 363 & 75.8 & 1.00 (referent) & 1.00 (referent) \\
\hline Yes & 47 & 9.8 & 116 & 24.2 & $2.94(2.04-4.25)$ & $2.70(1.85-3.94)$ \\
\hline \multicolumn{7}{|c|}{ Serious fight or argument with partner } \\
\hline No & 366 & 76.3 & 275 & 57.4 & 1.00 (referent) & 1.00 (referent) \\
\hline Yes & 114 & 23.8 & 204 & 42.6 & $2.38(1.81-3.14)$ & $2.40(1.78-3.17)$ \\
\hline \multicolumn{7}{|c|}{ Wedding of a close relative/friend } \\
\hline No & 415 & 86.5 & 409 & 85.4 & 1.00 (referent) & 1.00 (referent) \\
\hline Yes & 65 & 13.5 & 70 & 14.6 & $1.09(0.76-1.57)$ & $1.56(0.80-1.68)$ \\
\hline \multicolumn{7}{|c|}{ Any serious life event } \\
\hline No & 290 & 60.4 & 196 & 40.9 & 1.00 (referent) & 1.00 (referent) \\
\hline Yes & 190 & 39.6 & 283 & 59.1 & $2.20(1.70-2.85)$ & $2.21(1.69-2.90)$ \\
\hline 1 & 107 & 22.3 & 116 & 24.2 & $1.60(I . \mid 7-2.2 I)$ & I.64 (I.18-2.28) \\
\hline 2 & 61 & 12.7 & 116 & 24.2 & $2.81(1.97-4.03)$ & $2.75(1.90-4.00)$ \\
\hline $3+$ & 22 & 4.6 & 51 & 10.6 & $3.43(2.02-5.84)$ & $3.62(2.08-6.29)$ \\
\hline$P$ for trend & & & & & $<0.001$ & $<0.001$ \\
\hline
\end{tabular}

Note: *Adjusted for maternal age, prepregnancy weight, pregnancy not planned, and not receiving prenatal care.

Abbreviations: PTB, preterm birth; OR, odds ratio.

of preterm premature rupture of membranes, compared with women who experienced no such events.

The risk of very PTB $(<32$ weeks $)$, moderate PTB (32-33 weeks), and late PTB (34-36 weeks) in relation to maternal exposure to serious life events is shown in Table 4. Women who experienced the following life events: death of a first-degree relative or significant other, financial trouble or bankruptcy, or a serious fight with their partner, had higher odds of very PTB, moderate PTB, and late PTB. Experiencing a divorce or separation or experiencing a wedding of a close friend or relative was associated with increased odds of late PTB (adjusted OR 2.35; 95\% CI 1.16-4.76 and adjusted OR 1.59; 95\% CI 1.06-2.40, respectively). Compared with women who experienced no such events, those who experienced more than one serious life event had higher odds of PTB and the strength of association increased with increased occurrence of serious life events $\left(P_{\text {trend }}<0.001\right)$.

\section{Discussion}

Women in our study who experienced serious life events during pregnancy were more likely to deliver preterm.
Our analysis identified specific serious life events that were associated with PTB, and we also showed a linear relationship for the association of PTB with number of serious events experienced during pregnancy. Our findings are consistent with the results of studies that evaluated serious life events with $\mathrm{PTB}^{10,25}$ and differ from studies that found significant associations only when analyzing specific timing of exposure to an event during pregnancy ${ }^{11,14,26}$ and those where the associations did not reach significance. ${ }^{7,16,27,28}$ Studies identifying serious life events have typically been carried out in developed countries or among minority populations in the US. To the best of our knowledge, this is the first study examining the association of serious life events with PTB among Peruvian women.

Of the events included in our analysis, experiencing the death of a first-degree relative, separation or divorce, arguing or fighting with a partner, and financial troubles were each shown to significantly increase the odds of PTB for the women by more than two-fold. This pattern held true for preterm subtypes, spontaneous preterm labor, and preterm premature rupture of membranes. Investigators in a 
Table 3 Odds ratios and $95 \%$ confidence intervals of preterm birth subtypes according to maternal exposure to serious life events during pregnancy, Lima, Peru, 2009-2010

\begin{tabular}{|c|c|c|c|c|c|}
\hline \multirow[t]{2}{*}{ Life events } & \multirow{2}{*}{$\begin{array}{l}\text { Controls } \\
(n=480) \\
n\end{array}$} & \multicolumn{2}{|c|}{$\begin{array}{l}\text { Spontaneous preterm labor } \\
(\mathrm{n}=\mathbf{2 4 5})\end{array}$} & \multicolumn{2}{|c|}{$\begin{array}{l}\text { Preterm premature rupture of membranes } \\
(n=234)\end{array}$} \\
\hline & & $\mathbf{n}$ & OR* $(95 \% \mathrm{Cl})$ & $\mathbf{n}$ & OR* $(95 \% \mathrm{Cl})$ \\
\hline \multicolumn{6}{|c|}{ Death of a first-degree relative/significant other } \\
\hline No & 440 & 203 & 1.00 (referent) & 200 & 1.00 (referent) \\
\hline Yes & 40 & 42 & $2.50(1.55-4.04)$ & 34 & $1.73(1.03-2.89)$ \\
\hline \multicolumn{6}{|c|}{ Divorce or separation } \\
\hline No & 465 & 229 & $\mathrm{I} .00$ (referent) & 217 & $\mathrm{I} .00$ (referent) \\
\hline Yes & 15 & 16 & $2.25(1.07-4.74)$ & 17 & $2.03(0.97-4.26)$ \\
\hline \multicolumn{6}{|c|}{ Fired or forced to change job } \\
\hline No & 459 & 235 & 1.00 (referent) & 223 & 1.00 (referent) \\
\hline Yes & 21 & 10 & $\mathrm{I} .0 \mathrm{I}(0.46-2.23)$ & 11 & $1.13(0.52-2.46)$ \\
\hline \multicolumn{6}{|c|}{ Financial trouble or bankruptcy } \\
\hline No & 433 & 190 & 1.00 (referent) & 173 & 1.00 (referent) \\
\hline Yes & 47 & 55 & $2.58(1.66-4.00)$ & 61 & $2.91(I .87-4.5 I)$ \\
\hline \multicolumn{6}{|c|}{ Serious fight or argument with partner } \\
\hline No & 366 & 143 & 1.00 (referent) & 132 & 1.00 (referent) \\
\hline Yes & 114 & 102 & $2.4 I(1.7 I-3.40)$ & 102 & $2.41(1.70-3.42)$ \\
\hline \multicolumn{6}{|c|}{ Wedding of a close relative/friend } \\
\hline No & 415 & 207 & $\mathrm{I} .00$ (referent) & 202 & $\mathrm{I} .00$ (referent) \\
\hline Yes & 65 & 38 & $1.30(0.83-2.03)$ & 32 & $1.03(0.64-1.65)$ \\
\hline \multicolumn{6}{|c|}{ Any of the serious life events } \\
\hline No & 290 & 102 & 1.00 (referent) & 94 & 1.00 (referent) \\
\hline Yes & 190 & 143 & $2.29(1.65-3.18)$ & 140 & $2.19(1.56-3.08)$ \\
\hline 1 & 107 & 59 & $1.70(1.13-2.53)$ & 57 & $1.61(1.07-2.45)$ \\
\hline 2 & 61 & 57 & $2.73(1.76-4.26)$ & 59 & $2.89(1.85-4.53)$ \\
\hline $3+$ & 22 & 27 & $4.26(2.26-8.03)$ & 24 & $3.16(1.63-6.14)$ \\
\hline$P$ for trend & & & $<0.001$ & & $<0.001$ \\
\hline
\end{tabular}

Note: *Adjusted for maternal age, prepregnancy weight, pregnancy not planned, and not receiving prenatal care. Abbreviations: $\mathrm{Cl}$, confidence interval; OR, odds ratio.

US cohort study of African American and American Indian women reported that women identified partner-related, finance-related, and trauma-related items to be stressful. However, the authors found no evidence of a statistically significant association between the stress constructs evaluated and PTB risk. $^{7}$

There are a number of events that could be used as a measure of stress, but generally an event can be considered stressful if it is a challenge, whether physical or psychologi$\mathrm{cal}$, that threatens to alter the homeostasis of the individual. ${ }^{2}$ The three types of life events, ie, death of relative, partner troubles, and financial troubles, we found to be associated with PTB have been the focus of other studies. A populationbased study of 2.6 million pregnancies in Sweden examined the association of stress, as defined by having a family member die during pregnancy, and found that the risk for PTB was elevated when the event occurred during the 5th and 6th month of pregnancy (OR 1.24; CI 99\% 1.08-1.42). ${ }^{11}$ In Denmark, a population-based study of 1.38 million singleton live births assessed death or serious illness of a first-degree relative as the exposure and found that there was a significant association with birth weight but not with PTB. ${ }^{12}$ Partner-related serious life events were considered in a German study. The investigators found in a sample of 589 pregnant women that those who felt they were in a very unhappy partnership had twice as many PTBs compared with women who reported being in a happy partnership; ${ }^{29}$ however, due to small numbers, the results did not reach statistical significance. An integrative review aimed at identifying studies regarding the association between economic contraction (ie, loss of employment, reduced income) and birth outcome found that socioeconomic stressors were more strongly and consistently associated with birth weight. However, there was little to no evidence supporting associations of socioeconomic stressors with PTB. ${ }^{30}$ Another important point that merits consideration is that the standard list of events included experiencing the wedding of a close relative or friend, which is typically considered to be a positive experience. However, in a setting such as Lima, Peru, where culturally the family ties are strong, ${ }^{31}$ weddings 
Table 4 Odds ratios and $95 \%$ confidence intervals of preterm birth severity according to maternal exposure to serious life events during pregnancy, Lima, Peru, 2009-2010

\begin{tabular}{|c|c|c|c|c|c|c|c|}
\hline \multirow[t]{2}{*}{ Life events } & \multirow{2}{*}{$\begin{array}{l}\text { Controls } \\
(n=480) \\
n\end{array}$} & \multicolumn{2}{|c|}{$\begin{array}{l}\text { Very PTB } \\
32 \text { weeks }(n=135)\end{array}$} & \multicolumn{2}{|c|}{$\begin{array}{l}\text { Moderate PTB } \\
32-33 \text { weeks }(n=78)\end{array}$} & \multicolumn{2}{|c|}{$\begin{array}{l}\text { Late PTB } \\
34-36 \text { weeks }(n=266)\end{array}$} \\
\hline & & $\bar{n}$ & OR* $(95 \% \mathrm{Cl})$ & $\bar{n}$ & OR* $(95 \% \mathrm{Cl})$ & n & OR* $(95 \% \mathrm{Cl})$ \\
\hline \multicolumn{8}{|c|}{ Death of a first-degree relative/significant other } \\
\hline No & 440 & 114 & $\mathrm{I} .00$ (referent) & 65 & $\mathrm{I} .00$ (referent) & 224 & $\mathrm{I} .00$ (referent) \\
\hline Yes & 40 & 21 & $1.92(1.03-3.56)$ & 13 & $2.42(1.81-4.97)$ & 42 & $2.15(1.34-3.47)$ \\
\hline \multicolumn{8}{|c|}{ Divorce or separation } \\
\hline No & 465 & 125 & 1.00 (referent) & 74 & $\mathrm{I} .00$ (referent) & 247 & $\mathrm{I} .00$ (referent) \\
\hline Yes & 15 & 10 & $1.85(0.74-4.60)$ & 4 & $1.77(0.56-5.60)$ & 19 & $2.35(1.16-4.76)$ \\
\hline \multicolumn{8}{|c|}{ Fired or forced to change job } \\
\hline No & 459 & 132 & 1.00 (referent) & 71 & 1.00 (referent) & 255 & 1.00 (referent) \\
\hline Yes & 21 & 3 & $0.48(0.13-1.79)$ & 7 & $2.33(0.93-8.82)$ & 11 & $0.96(0.45-2.06)$ \\
\hline \multicolumn{8}{|c|}{ Financial trouble or bankruptcy } \\
\hline No & 433 & 101 & 1.00 (referent) & 62 & 1.00 (referent) & 200 & 1.00 (referent) \\
\hline Yes & 47 & 34 & $2.72(1.59-4.68)$ & 16 & $2.26(1.18-4.32)$ & 66 & $2.91(1.91-4.43)$ \\
\hline \multicolumn{8}{|c|}{ Serious fight or argument with partner } \\
\hline No & 366 & 84 & 1.00 (referent) & $4 I$ & 1.00 (referent) & 150 & 1.00 (referent) \\
\hline Yes & 114 & 51 & $2.03(1.31-3.16)$ & 37 & $2.95(1.78-4.90)$ & 116 & $2.5 \mathrm{I}(\mathrm{I} .8 \mathrm{I}-3.49)$ \\
\hline \multicolumn{8}{|c|}{ Wedding of a close relative/friend } \\
\hline No & 415 & $|2|$ & 1.00 (referent) & 73 & $\mathrm{I} .00$ (referent) & 215 & $\mathrm{I} .00$ (referent) \\
\hline Yes & 65 & 72 & $0.83(0.44-1.58)$ & 5 & $0.44(0.17-1.15)$ & 51 & $1.59(1.06-2.40)$ \\
\hline \multicolumn{8}{|c|}{ Any of the serious life events } \\
\hline No & 290 & 63 & 1.00 (referent) & 34 & 1.00 (referent) & 99 & 1.00 (referent) \\
\hline Yes & 190 & 72 & $1.72(1.13-2.62)$ & 44 & $2.03(1.23-3.36)$ & 167 & $2.65(1.92-3.65)$ \\
\hline I & 107 & 32 & $\mathrm{I} .45(0.87-2.42)$ & 20 & $1.67(0.90-3.07)$ & 64 & $1.80(1.21-2.68)$ \\
\hline 2 & 61 & 27 & $1.82(1.02-3.26)$ & 13 & $1.87(0.91-3.82)$ & 76 & $3.74(2.46-5.69)$ \\
\hline $3+$ & 22 & 13 & $2.88(I .29-6.4 I)$ & 11 & $4.78(2.01-11.3)$ & 27 & $3.96(2.11-7.46)$ \\
\hline$P$ for trend & & & 0.003 & & $<0.001$ & & $<0.001$ \\
\hline
\end{tabular}

Note: *Adjusted for maternal age, prepregnancy weight, pregnancy not planned and not receiving prenatal care.

Abbreviations: $\mathrm{Cl}$, confidence interval; OR, odds ratio; PTB, preterm birth.

place additional stress and consume resources from the entire family. Demand on resources, such as time and money, alters the homeostasis of the woman. Future research should include qualifiers for the events experienced.

We also found a significant linear increase in odds of delivering preterm with an increase in number of events experienced during pregnancy. Similarly, a prospective study carried out in the People's Republic of China in 2008 evaluated the effects of maternal exposure to serious life events, included financial, emotional, traumatic, and spousal-related events. After adjustment for confounders, the authors reported an increased risk of PTB, with increasing numbers of life events during the first and second trimesters. ${ }^{26}$ Experiencing more than one serious life event during pregnancy may impact PTB in part due to the cumulative effect of stress ${ }^{8}$ or may be due to the increased chance that any one of the events will occur at a time period when the pregnancy is more vulnerable to stress. Discussions around the timing and number of events occurring during pregnancy indicate that studies should also examine the type of psychosocial stress and perceived stressfulness of events experienced, as well as the cumulative impact of lifelong, chronic stress..$^{27,32}$ Our results, combined with those described previously, highlight the importance of investigating the association of serious life events with PTB, which is a growing public health concern. These results suggest that the risk of PTB may increase in women who experience one or more serious life events while pregnant. Future work should include prospective studies to explore the type and intensity of such events in order to understand the magnitude of maternal stress experienced.

Stress is thought to be involved in inducing preterm labor via behavioral pathways, such as poor nutrition or poor prenatal care. ${ }^{32,33}$ Stress may induce PTB via the physiological responses mediated by stress hormones and neurotransmitters. ${ }^{34}$ One pathway is related to cortisol, the hormone released by the hypothalamic pituitary gland in response to stress, which is also the hormone involved in normal parturition. ${ }^{34}$ As levels of cortisol rise, they prepare the physiological mechanisms for release of oxytocin, the 
hormone responsible for uterine contractions, and rising levels of cortisol due to experiencing stress may lead to an early rise in oxytocin, which in turn, may lead to early labor and delivery. ${ }^{33}$ Future research is needed to establish the biological pathway from stress to PTB, with a specific focus placed on understanding independent and interactive effects of exposures to stressors and genetic determinants of PTB among women in low, middle, and high income countries.

Several limitations should be considered when interpreting the results of our study. First, its cross-sectional nature prevents inference on any causal relationship between experiencing serious life events and PTB. The interview was conducted after delivery, allowing for possible recall bias regarding the events experienced. Second, the list of stressful life events may not have captured all possible serious life events, and we could not account for reverse causality in some items (ie, due to a difficult pregnancy, the woman may have been forced to change jobs or leave her job). Third, there was the possibility of substantial heterogeneity among the different types of serious life events. It is possible that the grouping of different types of life events in a single composite score might have attenuated the magnitude of the association towards the null. Future studies need to evaluate the impact of frequency, timing, and severity of serious life events on PTB. Additionally, the list of events is appropriate primarily for women who are able to have the experiences in the list, such as being familycentered and engaged in traditional partnerships. This list does not capture the serious events for women living beyond the range of these experiences. Finally, although we adjusted for confounding factors, we cannot exclude the possibility of some residual confounding by unmeasured factors.

\section{Conclusion}

Experiencing serious life events during pregnancy was associated with increased risk of PTB among Peruvian women. Interventions aimed at identifying and assisting women who are experiencing serious life events may reduce the risks of PTB. Future studies should consider perceived stress, exposure to stressors across the life course, and available social support that could mitigate the impact of such stress. Studies should also include objective measures of stress and the stress response to understand better the biological underpinnings of the observed associations.

\section{Acknowledgments}

This research was supported by awards from the National Institutes of Health, the Eunice Kennedy Shriver Institute of Child Health and Human Development (5R01-HD-059827 and 1R01-HD-059835), and National Institute of Minority Health and Health Disparities (T37-MD-001449). The National Institutes of Health had no further role in the study design, in the collection, analysis and interpretation of data, in the writing of the report, or in the decision to submit the paper for publication. The authors wish to thank the staff of the Hospital Nacional dos de Mayo, Instituto Especializado Materno Perinatal, and Hospital Edgardo Rebagliati Martins for their technical assistance with this research.

\section{Disclosure}

The authors report no conflicts of interest in this work.

\section{References}

1. Lawn JE, Gravett MG, Nunes TM, Rubens CE, Stanton C. Global report on preterm birth and stillbirth (1 of 7): definitions, description of the burden and opportunities to improve data. BMC Pregnancy Childbirth. 2010;10 Suppl 1:S1.

2. Simmons LE, Rubens CE, Darmstadt GL, Gravett MG. Preventing preterm birth and neonatal mortality: exploring the epidemiology, causes, and interventions. Semin Perinatol. 2010;34(6):408-415.

3. Blencowe H, Cousens S, Oestergaard MZ, et al. National, regional, and worldwide estimates of preterm birth rates in the year 2010 with time trends since 1990 for selected countries: a systematic analysis and implications. Lancet. 2012;379(9832):2162-2172.

4. Gravett MG, Rubens CE, Nunes TM. Global report on preterm birth and stillbirth (2 of 7): discovery science. BMC Pregnancy Childbirth. 2010;10 Suppl 1:S2.

5. Galea S, Vlahov D. Urban health: evidence, challenges, and directions. Annu Rev Public Health. 2005;26:341-365.

6. Coussons-Read ME, Lobel M, Carey JC, et al. The occurrence of preterm delivery is linked to pregnancy-specific distress and elevated inflammatory markers across gestation. Brain Behav Immun. 2012; 26(4):650-659.

7. Lu MC, Chen B. Racial and ethnic disparities in preterm birth: The role of stressful life events. Am J Obstet Gynecol. 2004;191(3):691-699.

8. Traviss G, Meer S, West R, House A. Life events and difficulties and their association with antenatal distress in White and South Asian women in the UK. Soc Psychiatry Psychiatr Epidemiol. 2013;48(5):725-734.

9. Kitsantas P, Gaffney KF, Cheema J. Life stressors and barriers to timely prenatal care for women with high-risk pregnancies residing in rural and nonrural areas. Womens Health Issues. 2012;22(5):e455-e460.

10. Badr LK, Abdallah B, Mahmoud A. Precursors of preterm birth: comparison of three ethnic groups in the Middle East and the United States. J Obstet Gynecol Neonatal Nurs. 2005;34(4):444-452.

11. Class QA, Lichtenstein P, Långström N, D’Onofrio BM. Timing of prenatal maternal exposure to severe life events and adverse pregnancy outcomes: a population study of 2.6 million pregnancies. Psychosom Med. 2011;73(3):234-241.

12. Khashan AS, McNamee R, Abel KM, et al. Rates of preterm birth following antenatal maternal exposure to severe life events: a populationbased cohort study. Hum Reprod. 2009;24(2):429-437.

13. Hedegaard M, Henriksen TB, Secher NJ, Hatch MC, Sabroe S. Do stressful life events affect duration of gestation and risk of preterm delivery? Epidemiology. 1996;7(4):339-345.

14. Torche F, Kleinhaus K. Prenatal stress, gestational age and secondary sex ratio: the sex-specific effects of exposure to a natural disaster in early pregnancy. Hum Reprod. 2012;27(2):558-567.

15. Lobel M, Cannella DL, Graham JE, DeVincent C, Schneider J, Meyer BA. Pregnancy-specific stress, prenatal health behaviors, and birth outcomes. Health Psychol. 2008;27(5):604-615. 
16. Abeysena C, Jayawardana P, Seneviratne Rde A. Effect of psychosocial stress and physical activity on preterm birth: a cohort study. J Obstet Gynaecol Res. 2010;36(2):260-267.

17. Sanchez SE, Alva AV, Diez Chang G, et al. Risk of spontaneous preterm birth in relation to maternal exposure to intimate partner violence during pregnancy in Peru. Matern Child Health J. 2013;17(3):485-492.

18. Seng JS, Low LK, Sperlich M, Ronis DL, Liberzon I. Post-traumatic stress disorder, child abuse history, birthweight and gestational age: a prospective cohort study. BJOG. 2011;118(11):1329-1339.

19. Carnero AM, Mejía CR, García PJ. Rate of gestational weight gain, prepregnancy body mass index and preterm birth subtypes: a retrospective cohort study from Peru. BJOG. 2012;119(8):924-935.

20. Ip M, Peyman E, Lohsoonthorn V, Williams MA. A case-control study of preterm delivery risk factors according to clinical subtypes and severity. J Obstet Gynaecol Res. 2010;36(1):34-44.

21. American College of Obstetricians and Gynecologists. American College of Obstetricians and Gynecologists Technical Bulletin. Preterm Labor. Number 206, Jun 1995 (Replaces No 133, October 1989). Int J Gynaecol Obstet. 1995;50(3):303-313.

22. Williams MA, Mittendorf R, Stubblefield PG, Lieberman E, Schoenbaum SC, Monson RR. Cigarettes, coffee, and preterm premature rupture of the membranes. Am J Epidemiol. 1992;135(8):895-903.

23. De B, Lin S, Lohsoonthorn V, Williams MA. Risk of preterm delivery in relation to maternal low birth weight. Acta Obstet Gynecol Scand. 2007;86(5):565-571.

24. Rothman KJ, Greenland S, Lash TL. Modern Epidemiology. Philadelphia, PA, USA: Wolter Kluwer Health/Lippincott Williams and Wilkins; 2008.
25. Tegethoff M, Greene N, Olsen J, Meyer AH, Meinlschmidt G. Maternal psychosocial adversity during pregnancy is associated with length of gestation and offspring size at birth: evidence from a population-based cohort study. Psychosom Med. 2010;72(4):419-426.

26. Zhu P, Tao F, Hao J, Sun Y, Jiang X. Prenatal life events stress: implications for preterm birth and infant birthweight. Am J Obstet Gynecol. 2010;203(1):34.e31-34.e38.

27. Littleton HL, Bye K, Buck K, Amacker A. Psychosocial stress during pregnancy and perinatal outcomes: a meta-analytic review. J Psychosom Obstet Gynaecol. 2010;31(4):219-228.

28. Neggers Y, Goldenberg R, Cliver S, Hauth J. The relationship between psychosocial profile, health practices, and pregnancy outcomes. Acta Obstet Gynecol Scand. 2006;85(3):277-285.

29. Rauchfuss M, Maier B. Biopsychosocial predictors of preterm delivery. $J$ Perinat Med. 2011;39(5):515-521.

30. Zilko CE. Economic contraction and birth outcomes: an integrative review. Hum Reprod Update. 2010;16(4):445-458.

31. Alesina A, Giuliano P. The power of the family. Journal of Economic Growth. 2010;15(2):93-125.

32. Hobel CJ, Goldstein A, Barrett ES. Psychosocial stress and pregnancy outcome. Clin Obstet Gynecol. 2008;51(2):333-348.

33. Cardwell MS. Stress: pregnancy considerations. Obstet Gynecol Surv. 2013;68(2):119-129.

34. Wadhwa PD, Entringer S, Buss C, Lu MC. The contribution of maternal stress to preterm birth: issues and considerations. Clin Perinatol. 2011;38(3):351-384.
International Journal of Women's Health

\section{Publish your work in this journal}

The International Journal of Women's Health is an international, peerreviewed open-access journal publishing original research, reports, editorials, reviews and commentaries on all aspects of women's healthcare including gynecology, obstetrics, and breast cancer. The manuscript management system is completely online and includes

\section{Dovepress}

a very quick and fair peer-review system, which is all easy to use. Visit http://www.dovepress.com/testimonials.php to read real quotes from published authors. 